
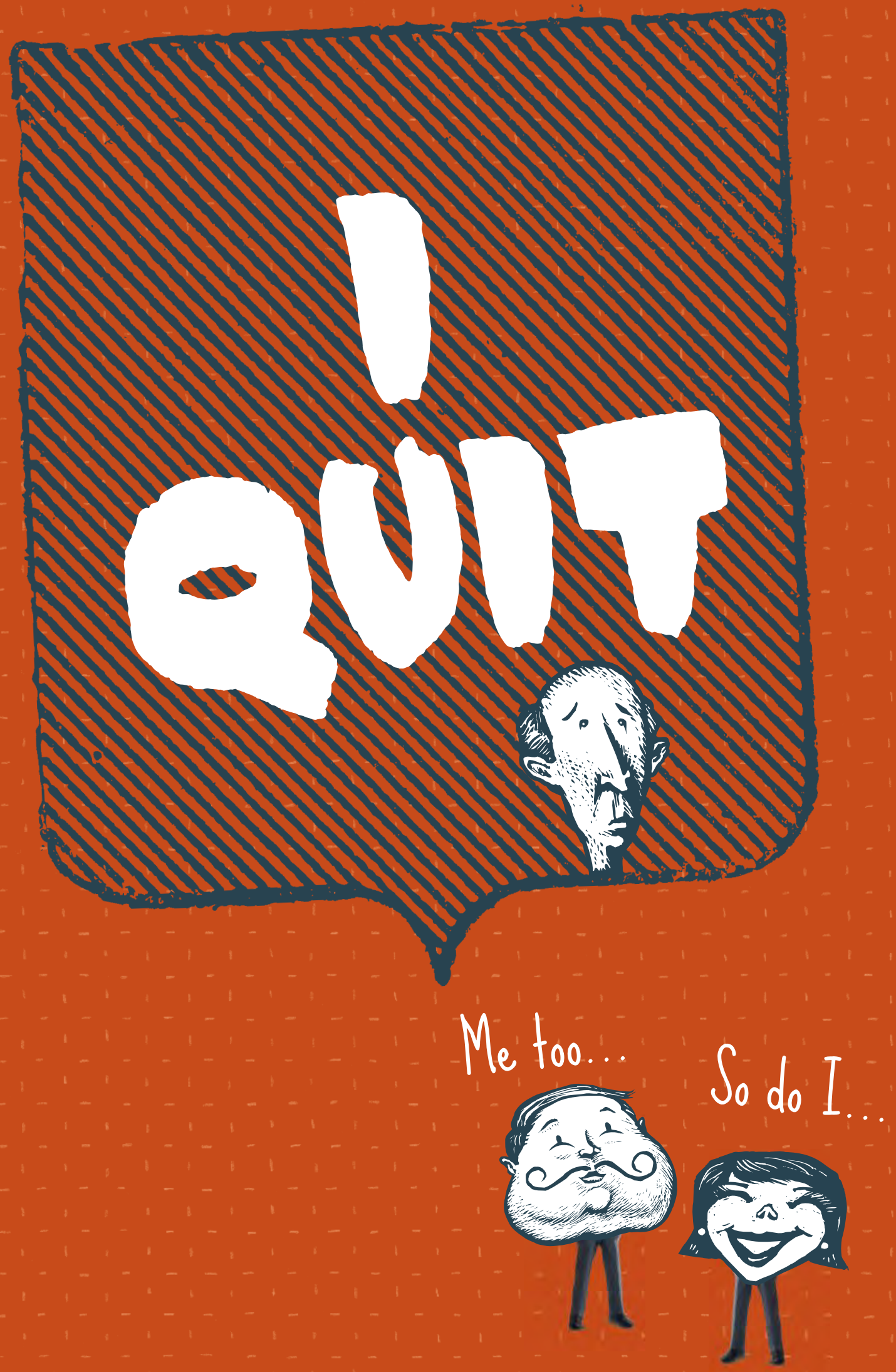


\title{
If You Go, I Will Follow ... Social Effects on the Decision to Terminate a Service
}

\author{
Irit Nitzan and Barak Libai
}

\author{
KEYWORDS \\ Customer Retention, \\ Customer Churn, Churn Prevention, \\ Social Network \\ THE AUTHORS \\ Irit Nitzan, \\ Assistant Professor of Marketing, \\ Recanati Business School, \\ Tel Aviv University, Tel-Aviv, Israel, \\ iritnitz@tau.ac.il

\section{Barak Libai,} \\ Associate Professor, Arison School of Business, \\ Interdisciplinary Center, Herzliya, Israel, \\ libai@idc.ac.il
}

The adoption of new behaviors or new products is often influenced by those closest to us. Whether it's new software, a vacation destination or a car - if a friend or neighbor likes it, consumers will likely be more inclined to try it for themselves and ultimately adopt it. But where does customer churn play into this? To what extent do our social interactions influence our decision to abandon a product or practice? Although retention and its drivers have attracted much research attention, few studies have focused on the role social factors play within the context of churn. In many studies, customer satisfaction and usage patterns have emerged as key elements that can explain churn, but mounting evidence suggests that attrition may also be influenced by one's peers. For example, the decision to quit smoking, to defect from military service or to quit a job is often prompted by social conditions, sometimes to a large degree.

Encouraged by such evidence, two marketing researchers conducted a large-scale analysis on customers of a cellular company, ultimately confirming that social effects are relevant to a customer's decision to end a business relationship. For this study, the researchers selected a sample of more than 1 million customers in a Mediterranean country and applied survival analysis techniques. The available data contained information on all calls and text messages sent or received by each customer over a three-month period, forming his or her social network within the provider's network. Customer churn was observed over a yearlong period during which $4.1 \%$ of all customers canceled their service. Figure 1 shows the 1 million customers' exposure to defecting neighbors, in this yearlong period. 


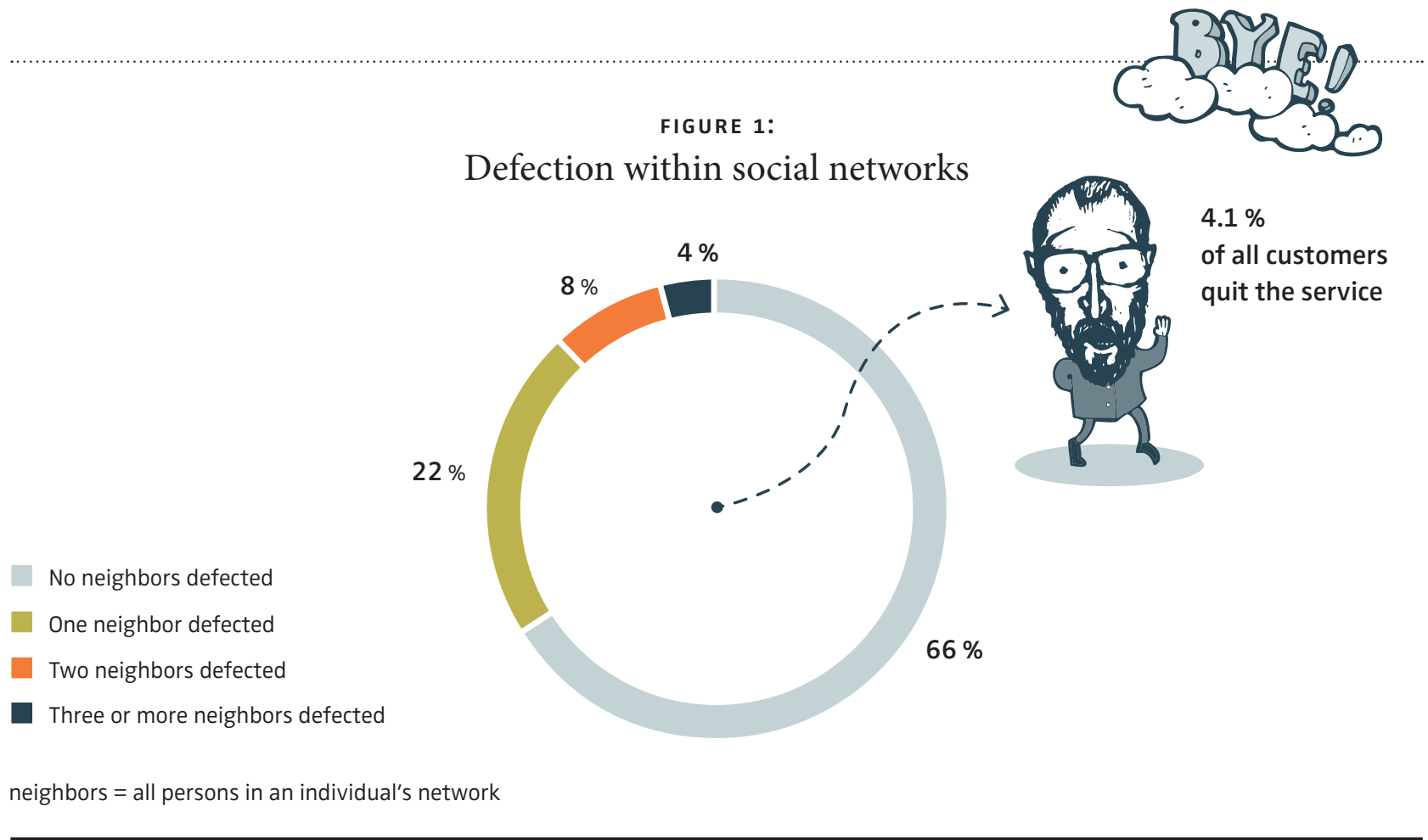

〉)

\section{Each defecting neighbor}

the focal customer was exposed

to was associated with a

$79.7 \%$ increase in this customer's

hazard of defection.
Social aspects strongly influence defection /// "Our research showed that each defecting neighbor the focal customer was exposed to was associated with a $79.7 \%$ increase in this customer's hazard of defection," co-author Irit Nitzan explains. "The observed effect was as pronounced as typical social effects on adoption, and even larger." This increase in what the study authors refer to as "hazard of defection" was evident even when taking into account traditional factors such as enhanced support consumption and reduced usage, which are known for their contribution to a customer's decision to defect. Including variables that reflect the defection decisions made by the network neighbors of each customer, notably improved the results in a model to predict whether the customer would churn. The researchers compared the percentage of customers predicted to defect with those who ultimately did defect, producing accurate predictions in $28.1 \%$ of all cases. The model relying on traditional defection factors succeeded only in $20.5 \%$ of the cases, which means that the social model increased the prediction's accuracy by $37.5 \%$.

Some network neighbors assert greater influence /// In addition to the actual number of network neighbor defections, other social network characteristics also affected the probability that customers would terminate their contract. 
> Hazard of defection increased with tie strength /// The more a customer communicated with a neighbor who had terminated service (i.e., the stronger their tie), the more likely the customer was to follow in the neighbor's footsteps. A $1 \%$ increase in a customer's average tie strength with defecting neighbors was associated with a $2.2 \%$ increase in that customer's hazard of defection. For example, if a customer's average tie strength with a defecting neighbor was $8 \%$, which was roughly the average tie strength among the study's subjects, the focal customer would be $17.6 \%$ more likely to defect.

$>$ Neighbors with similar characteristics had more influence /// Referral behavior often occurs among customers who resemble one another in terms of belief systems, education and occupation. Individuals are more likely to trust the endorsements of people whose preferences they share. In this study, the researchers used gender, age, segment and socioeconomic status to compare similarity. These were translated into similarity scores that ranged from 0 (no match on any of the four characteristics) to 100 (all four characteristics matched). For this criterion, a 1\% increase in a customer's average similarity with defecting neighbors was associated with a $1 \%$ increase in that customer's hazard of defection. For example, if a customer was exposed to the defection of a neighbor with whom he or she had one attribute in common (i.e., the pair's similarity score was $25 \%$ ), this exposure was associated with a $25 \%$ increase in the customer's hazard of defection.

$>$ Customers with greater numbers of social connections were more likely to defect but had less influence on the defection of others /// Each additional neighbor in a focal customer's local network was associated with an increase of $1.1 \%$ in that customer's hazard of defection. A user with 10 neighbors had a $3.3 \%$ higher hazard of defection than a user with only seven neighbors. This result resembles findings in adoption research, in which highly connected "network hubs" tend to adopt earlier. On the other hand, highly connected customers had a weaker influence than customers with fewer connections. On the other hand, highly connected customers had a weaker influence than customers with fewer connections. An increase of one additional social tie in the defecting neighbor's social network was associated with a $0.4 \%$ decrease in the focal customer's hazard of defection.

\author{
$\gg$ \\ Information on social influences \\ can substantially improve \\ the analysis of new product adoption, \\ and the same seems to \\ hold true for customer defection.
}

$\ll$

$>$ The effect of exposure to a defecting neighbor decreased over time /// The effect a neighbor's defection had on a focal customer's hazard of defection was strongest within the first month. Figure 2 shows how this variable's relationship to the focal customer's decision decreased as time passed.

> Loyal customers were less sensitive to negative comments from their defecting neighbors /// Moreover, customer loyalty helped "immunize" customers against the negative effects of others' defection: Heavy users and long-term customers were less influenced by defecting neighbors than light users and newcomers, respectively. Figure 3 compares the hazard of defection for heavy versus light users. Similarly, customers who used the service for less than two years showed a higher defection rate than those who had entered into a contract for the service more than seven years earlier.

> Advertising levels had no impact on customers' defection decisions /// By measuring how much companies allocate to their advertising budgets, the researchers investigated whether advertising helped to prevent defection. They observed that advertising had little to no effect on a customer's tendency to defect. 
FIGURE 2:

Hazard ratio as a function of time from the neighbor's defection

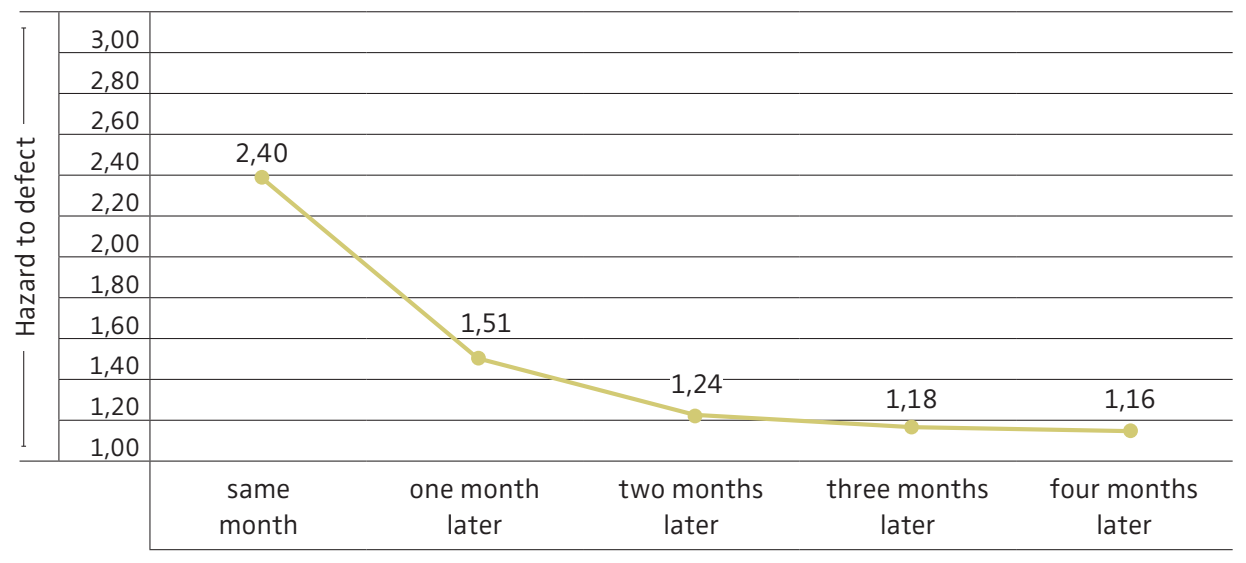

Time from a neighbor's defection

FIGURE 3:

Hazard ratio as a function of time from the neighbor's defection:

Heavy versus light users

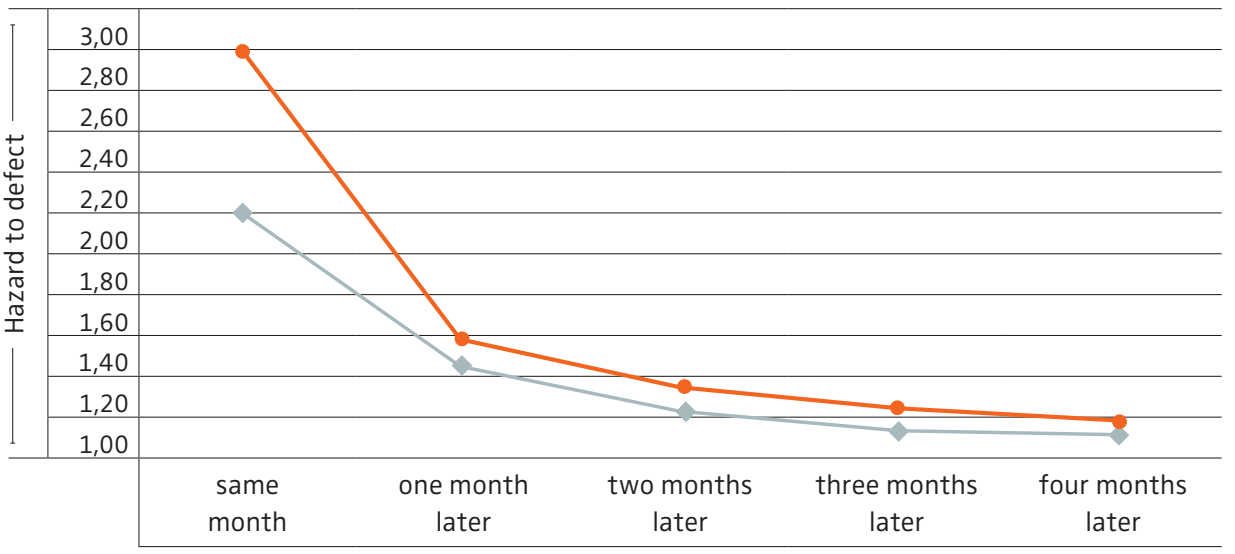

- Time from a neighbor's defection 


\section{Managerial implications}

$>$ The study results show that companies should take customers' social networks into account when attempting to predict and manage customer churn. Information on social influences can substantially improve the analysis of new product adoption, and the same seems to hold true for customer defection.

> Customers' exposure to defectors had a relatively strong influence on their defection decision. Therefore, it makes sense for companies to integrate such information into their analyses, even if precise network-related information on defectors and their neighbors, such as tie strength or similarity, is not available. Simply knowing about a defection may prompt a company to act.

> Companies intending to deal with the possible social fallout of a defection should act swiftly. Much of a defector's influence on his or her neighbors occurs during the first two months after defection. Therefore, a managerial response to customer defections should be undertaken as soon as possible.

$>$ The possibility of counteracting customers' defection decisions with advertising appears to be limited. Canceling service seems to be driven more by customers' own experiences and by those of their social neighbors than by advertising. Therefore, it might make more sense for a company to allocate a larger portion of its budget to more closely monitoring social variables than to retentiongeared advertising. For example, satisfaction surveys have traditionally focused on the individual; however, further examination of the satisfaction of a user's friends, either by asking the focal customer or through independent surveys, might provide fruitful results for more targeted churnpreventing measures.

$>$ While it is fairly easy to collect network data for cellular services, access to this type of information for other products and services is more difficult. Managers from other industries will have to investigate whether new technologies might provide opportunities to collect more data from their customers' social networks, for example through Facebook and other social networking sites. Another possibility could be to take advantage of the emerging use of brand and online communities to better assess the relationship between social behavior and defection.
The fundamental results presented in this summary should prove relevant for understanding social effects on customer retention in general, but the magnitude of this relevance might differ across industries. "Cellular phone services are characterized by relatively high customer involvement and possible normative pressure," co-author Barak Libai explains. "Markets with these characteristics, coupled with possible price-driven network effects, are likely to be associated with relatively strong social effects on attrition." This means such effects would be weaker in markets with lower customer involvement. On the other hand, cellular services are often characterized by contractual agreements that tend to curb users' desire to leave the service, even if they are persuaded to do so by others' word of mouth. Therefore lower switching costs in other markets may be associated with greater social effects on the retention decision.

\section{Managerial summary of an article published in the top academic journal "Journal of Marketing":}

Nitzan, Irit; Libai, Barak (2011): "Social Effects on Customer Retention", Journal of Marketing, Vol. 75, No. 6 , pp. $24-38$.

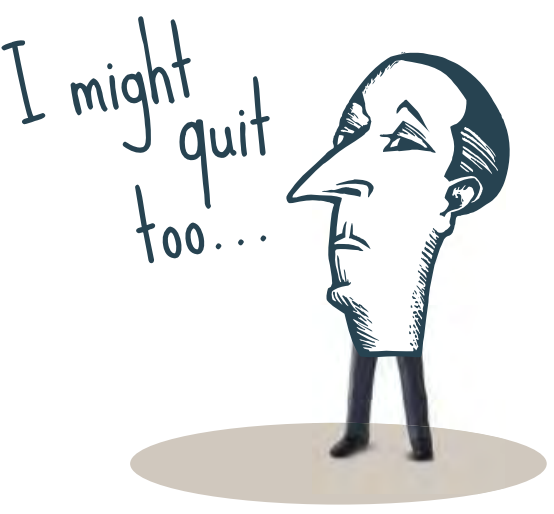

